\title{
Impacto de los fenómenos migratorios en el aula Interculturalidad y transgeneracionalidad
}

\author{
Impact of migratory phenomena in classrooms \\ Intercultural and transgenerational
}

Patricia Cesca*

\section{RESUMEN}

Este artículo tratará de dar visibilidad al malestar identitario resultante de la tensión de estar en la frontera, en el "entre" culturas (lo intercultural) con los deseos encontrados de cumplir con las expectativas de las generaciones anteriores (lo transgeneracional), a partir de la inserción de estudiantes de origen taiwanés en escuelas de la ciudad de Buenos Aires. El escrito se centra en jóvenes, adultos y adultos mayores taiwaneses, en tanto actores de una transmisión transgeneracional e intercultural que modifica el carácter monolítico de la cultura originaria, no sin padecimiento y llevándolos a inventar y reinventar sus identidades para tramitarlo. Se consideran centralmente como marcadores teóricos estratégicos los aportes de la pedagogía crítica y de la socioantropología, junto con un modo de concebir la subjetividad que deviene del campo del psicoanálisis. Se inscribe en una tradición de estudios que investigan las demandas que reciben las escuelas ante las transformaciones producidas por la renovada y creciente presencia de personas de orígenes diversos en sus aulas, en el marco de un mundo globalizado.

Palabras clave: estudiantes inmigrantes, interculturalidad, transgeneracionalidad, malestar identitario

\begin{abstract}
This article will treat it focusses on the tension it means to stand between cultures (interculturality), wishing to comply with the expectations of the former generations (transgenerationality), from the inclusion of Taiwanese students in schools of the city of Buenos Aires. This written is concentrating on young, adult and elderly Taiwanese people, who have become the actors of an intercultural and transgenerational transmission, that modifies the monolitic character of the original culture, and not without suffering, leading them to inventing and re-inventing their own identities 50 as to be able to transmit it. The contribution of the critical pedagogy and the socioantropology, together with a way of facing subjectivity derived from psychoanalysis are considered theoretical strategic markers. All this within a tradition of studies about the demands that the school faces due to the changes produced by the renewed and growing presence of people from different origins that integrate the classroom in terms of a globalized world.
\end{abstract}

Key words: immigrant students, intercultural, transgenerational, identity malaise

\footnotetext{
"Profesora en Ciencias de la Educación por la Universidad Católica de Argentina; mariapcesca@gmail.com
} 


\section{INTRODUCCIÓN}

En el curso de una investigación (2008-2010) para un trabajo de tesis, ${ }^{1}$ pusimos foco en el cruzamiento de lo universal (las migraciones) lo particular (la migración taiwanesa) y lo singular (las subjetividades que se inventan, tramitan, sufren...) que a su vez se da dentro de otro cruce entre transgeneracionalidad ${ }^{2}$ e interculturalidad $^{3}$ en un ámbito como la escuela.

Nos ocuparemos en este artículo de lo singular, situado en aspectos de lo particular que atañen a la migración de estudiantes de origen taiwanés. Cabe, en este punto, clarificar que hablar de la inmigración taiwanesa fue un caso arquetípico que nos permitió una lectura de las vivencias de sufrimiento y discriminación que padecen los jóvenes inmigrantes (de cualquier procedencia) en las escenas escolares.

Sucede que los procesos migratorios se constituyen, en ocasiones, para discernir el andamiaje que da lugar a identidades interculturales. Discernir qué de la mirada de los Otros constituye "lo que somos", el "mí mismo", el "quién soy" y "el quién no soy", "de dónde vengo" y nos permite contemplar las fallas y fisuras ineludibles.

Nuestra primera hipótesis es que la transmisión de adultos portadores de culturas aferradas a un pasado que pretende perpetuarse, realizada a niños y jóvenes, provocaría malestar identitario ya que estos se debaten entre lo aprendido por la socialización fa-

\footnotetext{
${ }^{1}$ Titulada "Escuela y migraciones. Discriminación y malestar identitario en relaciones transgeneracionales e interculturales. El caso de jóvenes inmigrantes taiwaneses". Dirigida por la Dra. Perla Zelmanovich.

${ }^{2}$ Según Isidoro Berenstein (2000) lo transgeneracional es la cadena de transmisión de significaciones que se lega de generación en generación y que abarca ideales, mitos, modelos identificatorios y enunciados discursivos que involucran lo dicho, pero también lo que se omite por efecto de represión, de manera que tales enunciados adquieren la fuerza de mandatos cuya determinación es inconsciente. Lo inconsciente aspira a irrumpir y por lo tanto guarda una eficacia potencial a través de la transmisión generacional.

${ }^{3} \mathrm{La}$ interculturalidad será concebida, en este escrito, como una perspectiva dinámica de la cultura y las culturas que da cabida a interacciones intelectuales, subjetivas y culturales, no exentas de contaminaciones, diálogos y conflictos como resultado de estar "entre culturas". Para superar la contradicción entre cultura y universalismo, este término no define la coexistencia de culturas mónadas decretadas iguales en cuanto a su dignidad, sino la posibilidad, ofrecida constantemente a los individuos, de atravesar universos culturales diferentes.
} 
miliar y la escolar, donde se juegan sus procesos de subjetivación en un escenario sociocultural muy diferente al de sus antecesores.

Del amplio campo de publicaciones sobre los estudiantes inmigrantes y las performances o actuaciones escolares, así como investigaciones pertinentes a estas temáticas, solo tomaremos, en este artículo, aquella bibliografía que consideramos habilitaba una respuesta aproximada a la preguntas que nos plantea Hannah Arendt (1954): ¿cuánto la educación tiene que ver con el amor por los demás, hasta tal punto de que educamos para que esos demás, esos otros, no queden librados a su propia suerte?

\section{DESCRIPCIÓN DE LA INVESTIGACIÓN}

Cuando pusimos foco en el cruzamiento de lo universal (las migraciones) lo particular (la migración taiwanesa) y lo singular (las subjetividades que se inventan, tramitan, sufren...) que a su vez se da dentro de otro cruce entre transgeneracionalidad e interculturalidad en un ámbito como es la escuela, decidimos consultar a personas que pertenecían a tres generaciones:

- Generación I adultos mayores: entre 60 y 80 ańos. Nacieron en Taiwán ${ }^{4}$ y llegaron ya grandes a Buenos Aires. Cursaron estudios primarios (no secundarios ni superiores) en su ciudad de origen. La mayoría no habla español

- Generación II adultos: entre 30 y 45 años. Nacieron en Taiwán y vinieron niños con sus padres a Buenos Aires. Algunos se insertaron y otros comenzaron en escuelas argentinas

- Generación III jóvenes: sus edades oscilaban entre los 19 y 25 ańos. Nacieron en Buenos Aires de dos padres taiwaneses. Asistieron íntegramente a escuelas argentinas. Actualmente se encuentran cursando la Universidad.

Durante la investigación se trató de entrar en diálogo con interlocutores atravesados por experiencias transgeneracionales e interculturales. No se trataba de informadores, sino de hablantes, sujetos movidos por una serie de afecciones que impactan de

\footnotetext{
${ }^{4}$ Durante este escrito usaremos indistintamente la expresión "chinos" o "taiwaneses", ya que, en realidad, Taiwán forma parte de la llamada China insular.
} 
modo singular en su subjetividad. El interés en los individuos no fue considerándolos como sujetos únicos, sino como tipos representativos.

Como plantea Giles Deleuze (2003), "en las totalidades no hay nadie". No es que la totalidad no exista, pero solo se da en sus modos de expresión. Nuestra encarnadura tuvo nombres: L, $\mathrm{M}, \mathrm{K}, \mathrm{T}, \mathrm{F}$, e $\mathrm{Y}$, que asumen la forma de una " $\mathrm{x}$ ", un enigma que nos enfrentaba a situaciones con signos poco descifrables y nos conecta con huellas o señales que ponen a prueba nuestra capacidad de acción y de pensamiento.

Dada la complejidad de las variables involucradas, la propuesta epistémica y empírica en cuanto al abordaje que se plantea se fundó en un enfoque transdisciplinario, en tanto no se trató de una suma de perspectivas, sino de una lectura de las experiencias inserta en una red de saberes en evolución constante en cada una de las disciplinas involucradas, las que se confrontan con sus propios límites. Se consideraron centralmente, como marcadores teóricos estratégicos, los aportes de la pedagogía crítica y de la socioantropología, junto con un modo de concebir la subjetividad que deviene del campo del psicoanálisis. Se inscribió en una tradición de investigaciones cualitativas que estudian las demandas que reciben las escuelas argentinas ante las transformaciones producidas por la renovada y creciente presencia de personas de orígenes diversos en sus aulas.

Optar por conceptos como "transgeneracional”; "intercultural", "escuela" para investigar el encuentro entre la transmisión de la generación de adultos mayores y adolescentes; entre la cultura taiwanesa y la cultura argentina implicó poner un zoom en el intercambio de bienes culturales y la interrelación entre grupos y sujetos de dos culturas con diferentes códigos semióticos, diferente manejo y uso de signos (significantes y significados) y, constatar el malestar, la discriminación, el sentimiento de pérdida y tristeza en quienes participan de dichos procesos, para finalmente situarlos en la lógica escolar. Se trató de colocar bajo una lupa que amplifica su entramado, haciendo visible lo que a simple vista no es evidente (como lo propone el Paradigma de inferencias indiciales acuñado por el historiador Carlo Ginzburg) y permite poner en discusión sus mecanismos de producción. 
Desplegamos distintas metodologías que detallamos a continuación:

a) El trabajo etnográfico: tuvo basamento en la participación en aquellos espacios de concurrencia frecuente por parte de los miembros de esta comunidad, y permitió cumplimentar, con fecundidad, la intención de esta investigación. El trabajo de campo consistió en integrarse a la celebración cristiana (una en taiwanés y otra en español) y luego participar del almuerzo comunitario y la sobremesa, sin que mediara una estrategia de recolección determinada. Se trataba de situarse desde otro ángulo de percepción de esta realidad para conocerla en su cotidianeidad

b) Entrevistas: se adoptó la modalidad de entrevistas en profundidad o etnológica, sugeridas por Homero Saltalamacchia (1997). Se parte de un plan general de preguntas sobre el tema a encarar, dejando que sea el entrevistado quien desarrolle los temas en profundidad. Las entrevistas se suceden en un mismo escenario cultural en el que funcionan el templo, la escuela y el comedor comunitario. A través de estas, no se apuntaba a agotar todos los temas, sino a delimitar un plano más complejo que el de las referencias a experiencias vividas. La aspiración de estas indagaciones es, para decirlo en términos weberianos, comprender el sentido de la acción en el plano de sus motivaciones, interacciones y modos, en los que las situaciones contextuales (sociales e institucionales), se hacen presentes, marcan rastros que podremos recuperar como inferencias indiciales. Las entrevistas no fueron analizadas en términos de la validez empírica de los enunciados y argumentaciones, sino en cuanto estrategias de recolección de datos observables para estructurar la argumentación de estos actores. Se realizaron en total 13 entrevistas de 45 a 60 minutos de duración.

c) Registros etnográficos: siguiendo a Rosana Guber (1991), el registro es la manifestación concreta del proceso de cómo el investigador concibe al campo y cuanto sucede en él. Para este trabajo se usó la grabación de entrevistas, buscando la mayor fidelidad, acompańada de toma de notas. Sucedió en 
la mayor parte de las mismas que, una vez apagado el aparato, el entrevistado seguía comentando temas surgidos durante la aplicación de la técnica, o haciendo expresiones que en ese momento nos parecían "cabos sueltos", todavía inasibles. También se sucedían gestos, expresiones faciales y corporales, movimientos y reacomodamiento, eventos antecedentes y consecuentes que el equipo grabador no podía captar. En sendos casos se apeló a la toma de notas, al narrar la experiencia en solitario ("bitácoras de la investigación") post entrevistas, tratando de reconstruir a posteriori, a través de las asociaciones que nos suscitaban los hechos empíricos que observamos. Consideramos importante el contacto visual en tanto prerrequisito para establecer una relación de confianza, proximidad y soltura. Escudrińar entornos, ver actividades y movimiento de las personas, los datos acústicos que venían a complementar los datos verbalizados por el entrevistado. Por esta razón optamos por combinar ambos procedimientos.

d) El Paradigma de inferencias indiciales: desarrollado por Carlo Ginzburg (1986), está basado en la búsqueda de particularidades menos trascendentes, imperceptibles para la mayoría, poco apreciadas o inadvertidas, que vienen a constituirse en "indicios" por medio de los cuales accedemos a operaciones intelectuales que conducen a la elaboración de conjeturas y que además nos posibilitan descifrar o leer mensajes emitidos por una realidad determinada. Indicios que son señales que nos permiten deducir, desde ciertas vinculaciones conceptuales, la construcción de relaciones entre aspectos fragmentados, ocultos, o no manifiestos de la vida social. A partir de las idas y venidas en la decisión del tema, las entrevistas, las observaciones, los registros, durante la escritura... puede afirmarse que el campo se amplió más allá de lo previsto. Durante dos años, los ojos, los oídos, el olfato... se sensibilizaron a todo lo que era "chino". Ver cruzar por la calle a alguien de rasgos orientales y mirar su vestimenta, su forma de caminar, inferir si era coreano o chino, chino o taiwanés; entrar a distintos supermercados chinos y estar alerta a los intercambios lingüísticos (aunque no los comprendiera) entre los dueños, entre los dueńos y los empleados y viceversa, entre los dueños 
con los clientes; estar atendiendo las noticias publicadas en cualquier diario o transmitidas en algún noticiero, referidas a China o Taiwán; mirar vidrieras o curiosear en las casas de regalería o venta de ropa para identificar los colores preferidos; "viajar" a China caminando por el barrio chino en reiteradas oportunidades a modo de resituar el conjunto de su tejido social. Durante un año vivimos en "la sociedad de la entrevista" (Paul Atkinson y David Silverman, 1997).

e) Análisis transgeneracional: fue utilizado como una estrategia para explorar las formas de la transmisión a través del tiempo. La aplicación de la metodología transgeneracional permite acercarse al estudio del problema de la historicidad, de la memoria colectiva del grupo de inmigrantes taiwaneses estudiado. El interés en este procedimiento consistió tanto en la indagación de visiones sobre los procesos de transmisión cultural taiwanesa en Argentina, como en las inserciones de los jóvenes de la generación más joven en los distintos mundos de sentido, en las relaciones sociales y en las posibles contradicciones derivadas del entramado que supone esa transmisión por adultos mayores que conocieron situaciones muy distintas.

f) Relatos de vida: recurrir a un abordaje a partir de los relatos de vida constituyó una lente distintiva para ubicar a los sujetos investigados en su contexto temporal, subrayando cómo sus vidas y su conocimiento han ido cambiando a lo largo de las generaciones. Fue de suma importancia acercarse al conocimiento de las trayectorias de los sujetos en cuanto indicios de los sistemas de relaciones en los que están insertos. Los relatos se configuran a partir del discurso oral de los interlocutores.

g) La deconstruccion derridariana: habilitamos un tipo de pensamiento que revisara insistentemente cada enunciado producido por los entrevistados y permitiera enlazar conceptos a las palabras expresadas por ellos poniendo, a su vez, a prueba y de manera permanente, dichos conceptos. Durante el proceso de deconstrucción se realizó una operación de mucho recaudo, procurando separar los enunciados de los entrevistados de aquellos provenientes del contexto sociocultural argentino, que generan estigmatización ("no les interesa Argentina, solo 
están de paso...") que se construyen con los significantes ${ }^{5}$ hegemónicos de una cultura y, si no se los cuestiona, pueden colocar una lente que empañe las lecturas del objeto de estudio.

h) Las nuevas tecnologías como estrategias de búsqueda: no puede obviarse destacar las facilidades de recolección de datos que posibilitó el Google en cuanto economizó tiempos y esfuerzos direccionándolos a aquellos datos que, de no haber sido por este buscador, quizá hubieran resultado inaccesibles. En ese mismo orden está la comodidad de las comunicaciones vía e-mails para agendar entrevistas, completar información y el uso del Facebook, fuente alternativa de información sobre aspectos de la vida de los entrevistados de la tercera generación.

Cada uno de los tópicos conceptuales seleccionados dio un lugar a los dichos de los sujetos y las situaciones puestas en relieve y experimentadas en las que se basó este esfuerzo metodológico, que permitió apreciar que, pese a la multiplicidad de discursos que hoy circulan sobre la interculturalidad, los docentes se encuentran, en gran medida, imbuidos de una lógica de transmisión homogeneizadora, tienen dificultad para salirse de ella y transmitir un horizonte intercultural.

\section{LA TRAMA DEL MALESTAR IDENTITARIO}

Desterritorialización, plurianclaje, identidades múltiples, lealtades escindidas... son demasiadas vivencias traumáticas que no pueden sino dar lugar a un malestar. Entendemos que, el malestar que nos convoca, se daría en dos dimensiones: una vinculada a factores de orden social-cultural-institucional y otra vinculada a factores de tipo psíquico. En la intersección entre ambas dimensiones localizamos los procesos de subjetivación que se encuentran hoy atravesados por lo que Michel Autès (2004), llama "riesgo de desligadura" y que atañe a la dimensión simbólica de sentirse "no soy de aquí, ni soy de allá" como una de las formas de este malestar.

\footnotetext{
${ }^{5}$ Según Lacan, el significante es el elemento significativo del discurso que determina los actores, las palabras y el destino del sujeto sin que él lo sepa (Roudinesco y Le Plon,1977).
} 
A mi papá le molesta que me vea mucho con mis amigos, que los llame. Me dijo "te estás pareciendo cada vez más a los argentinos". Yo le contesté: “¡Ya sé lo que quieres, quieres que viva estudiando, que no tenga más amigos ni contacto con otros seres humanos que no sean chinos!".

M. Generación III

En estas palabras se hace notoria la tensión de estar en la intersección entre lo que "soy y no soy".

Por otro lado, las conceptualizaciones identitarias que se manifiestan en fórmulas del tipo "los bolivianos son... los taiwaneses son... o los argentinos son..." constituyen modos de tipificación que dificultan prácticas interculturales. Se trataría quizá de desplegar una suerte de fuerza de permisión, de autorización, que a su vez dé lugar a oportunidades que hacen posible al sujeto asumir que su origen no deviene en una condena: "Solo puedes ser boliviano". "Solo puedes ser taiwanés". "No sos argentino". Posicionamientos docentes representados en ese tipo de frases encubren una perspectiva expulsiva que dificulta a estos jóvenes una salida transicional. Así, Inés, María, Luis., Eduardo, es reemplazado por "la china", "el boliviano"...

Nuestros abuelos vivían una época más dura. Para obtener algo siempre tuvieron que sacrificarse. Nosotros también tendríamos que hacer lo mismo; si queremos un día tener una buena vida, tenemos que ahora pagar el precio, estudiando o cosas así.

F. Generación II

Surge de este registro la idealización de lo que quedó atrás y el sentido de deuda simbólica con los adultos mayores. A ello se suma el padecimiento que supone viajar a un país con un idioma distinto o que, a pesar de proceder de zonas muy diversas de Taiwán (de la capital, de un pueblo), refuerce la pertenencia: "soy taiwanés".

Esta cuestión se evidencia cuando los jóvenes de la Generación II necesitaron, para su desenvolvimiento en la escuela, apropiarse de nuevos códigos lingüísticos y culturales para entrar en contacto con sus pares del contexto educativo en el que se desenvolvían. Esto nos remite a la idea de las identidades como resul- 
tantes de una producción sociohistórica (Ian Hunter, 1994) que se dislocan de un contexto cultural y se recontextualizan en otro.

Pero el punto es que la fisonomía física es la que los rige. Es el caso de mi alumna, nació en Argentina, pero acá en la escuela le decían "la chinita". Cuando fue a Taiwán por un año, allá le decían "argentina”, entonces (ella) decía "en ningún lado me llaman como debería ser, porque acá, aunque soy argentina me dicen china, y en Taiwán lo contrario. Parezco un paria, no tengo patria, en ningún lado me reconocen como parte de ese lugar."

Docente, escuela argentina

Nació acá, en un ambiente occidental. Yo soy de apariencia oriental, pero yo soy occidental: ¿Quién soy yo? Chino, no soy. Argentino, tampoco soy; ¿qué soy? Es un problema. En un día, los sábados en la escuela china, no se le puede enseñar a ser chino. Ya tienen sus rasgos de nacimiento. Aunque sea un argentino, un brasileño, su apariencia es de oriental

Docente, escuela china

Tenemos que reconocer que, para los inmigrantes orientales, precede a la diferencia cultural una diferencia fenotípica, y a ellos se suma el bilingüismo chino/español que refleja dos filiaciones culturales con sus respectivos modelos de pensamiento: las lealtades múltiples, vivir en medio, en la grieta de dos mundos en que se dividen (y a veces se desgarran) las identidades. Podemos hablar de sentimientos inconscientes de bigamia de patrias, bipatrismo que caracteriza el sentir de buena parte de los inmigrantes.

Para nosotros, estar en dos lugares comporta la idea de lo intercultural como disyunción, como ser taiwanés y argentino y no taiwanés o argentino. La pregunta es ¿cómo nombrar la invención singular del sujeto que supere esa disyunción; los docentes ¿estarán formados y con herramientas para actuar ante la producción de una subjetividad hecha de múltiples identificaciones? ¿Cómo se ubica la escuela frente a estos dilemas? ¿Qué tipo de lealtades habilita la escuela? 


\section{ANÁLISIS DE CASOS}

Analizaremos tres casos que permiten ubicar el malestar identitario bajo la forma de ambigüedad en el que se pone en tensión lo intercultural y lo transgeneracional.

\section{Caso 1. ¿Quién soy? ¿Quién no soy?: C, ${ }^{6}$ generación III}

$\mathrm{I}^{7}-¿$ Cómo te sientes? ¿Argentino o taiwanés?

C -Es como que estoy ahí, en el medio, nunca fui totalmente argentino, ni totalmente taiwanés. Es más, tuve en algún momento de mi vida rechazo por lo taiwanés. No es mi patria, pero tampoco puedo aceptar, cien por cien, que Argentina sea mi patria, porque uno tiene que agradecer de dónde viene.

Elocuente fue que insistiera en clarificar una y otra vez este tema. Ello evidencia la angustia ligada a las deudas generacionales, a partir de esta pregunta, que él escucha “¿de qué lado estás?”. Lo que cuenta aquí, no obstante, no es la persona, sino las operaciones que se movilizan a partir de la palabra ajena.

Los funcionarios públicos, cuando vas a hacer algún trámite en el registro civil, te responden mal, te hablan mal y piensan que no sabes. Yo le digo a mi madre "voy a hacerle juicios a todos". Me da una bronca eso. Si yo no lo traté mal, no tiene por qué tratarme mal. Uno tiene que buscarse su lugar y mantener el límite del otro y decirle "no, a mí me respetas porque yo te respeto", si no, te pasan por arriba. Quizás en todos lados, más que nada, porque uno es el intruso del país, por eso te tratan mal, te quieren echar, te dicen "por qué no te vas a tu país", cosas así.

C. vive por sí mismo la necesidad de reconocerse y a veces de hacerse reconocer como ciudadano de derecho, al mismo tiempo que se considera un intruso. La figura de intruso nuevamente nos remite a la idea de constitución subjetiva a partir de los otros.

\footnotetext{
${ }^{6}$ Usamos siempre nombres ficticios.

7 "I" designa al entrevistador.
} 
¿Quién soy? Eso forma parte de mi angustia, definiéndola con cierta exageración, la angustia por no encontrar una posición bien definida, de decir soy de tal lugar. Y no decir "soy argentino, pero mis padres son taiwaneses". Esa no correspondencia a ninguno de los dos lugares

Creo que más que nada es una lucha interna mía, entre lo que la sociedad considera, la importancia que yo le doy a lo que ella opina y lo que yo quiero inconscientemente. ¡Es tan difícil salir de esa revolución!

Mi hijo nació acá en Argentina y creció acá, ya no se podría adaptar a Taiwán. El clima es distinto; aparte, como Taiwán es muy chico, no sería muy fácil conseguir trabajo entre tantos habitantes. Y después, otro tema sería el idioma, su chino no sería tan bueno como un nativo; entonces, eso influenciaría negativamente en su búsqueda de trabajo.

Habla la Madre (Generación I)

En este sentido, “¿quién soy?” podría presentarse para los jóvenes de la generación II y III como el modo de reconocer esa ambigüedad en su propia historia. Se trata del padecimiento de estar expuesto a una forma de vida que experimenta una especie de no sentirse en casa, identidades en tránsito. Elise Pestre (2009) ańade la idea de una reterritorialización del malestar.

En este punto se nos plantea una cuestión: ¿cómo elaborar una crisis estructural, propia de cualquier adolescente, sumado al hecho de vivir en esta ambigüedad?

Guy Bajoit (2009) nos ayuda a responder cuando hace la distinción de las identidades constituida por tres áreas articuladas entre sí: las identidades deseadas, las identidades asignadas y las identidades comprometidas.

- Las identidades deseadas contienen todo lo que el sujeto, consciente o inconscientemente, "siente" en sí mismo como deseos de ser o de hacer, todo lo que lo "impulsa" hacia sus preferencias, sus gustos y sus inclinaciones.

Probablemente no logre ser alguien sobresaliente el día de mañana, pero no pierdo nada con intentarlo. No existen cosas imposibles. Ser joven es responder por los actos propios 
- Las identidades asignadas contienen todo lo que el sujeto percibe, explícita o de modo confuso, como las expectativas de los demás con respecto a sí mismo (sus padres, sus docentes, sus compañeros) y/o instituciones (la escuela, la iglesia, el mercado de trabajo, el Estado...); es lo que él cree que su medio social espera de él, y que ha interiorizado en su conciencia moral.

Según mamá, las responsabilidades en las pequeñas cosas (como el colegio), hablan de la persona que eres. Las materias en el colegio eran la disciplina y el desafío, lo que me llevaba a tener altas calificaciones. Era el compromiso implícitamente adoptado como deber de estudiante

- Las identidades comprometidas se componen de los deberes (conscientes o no) que la persona siente para con sus tradiciones: sobresalir en su rendimiento y, por ejemplo, ser bueno en matemáticas, así como también sobre lo que en el presente es y hace. Lo que asume con respecto a sí mismo, a propósito de lo que, en el futuro, quiere ser y hacer. Es la imagen que se forma de sí mismo en el tiempo, cuando dice en otro tramo: "Me tira tan abajo el hecho de que me vaya mal en matemáticas"; es lo que cree debe ser y hacer para ser coherente con sus antecesores (hábiles en matemáticas) así como para salvaguardar su integridad identitaria.

Hay dos medios que te hacen llegar a ser alguien, el dinero o el conocimiento. Como dinero no tenía, me decidí por el conocimiento como medio, por eso estudiaba y procuraba mantenerme como un buen alumno. Ser buen alumno no asegura un futuro, pero a veces puede llegar a aumentar las probabilidades.

Estas tres áreas identitarias se recubren de modo parcial: lo que el sujeto espera de sí mismo solo coincide en parte con lo que los demás esperan de él y, por consiguiente, necesita siempre "traficar" entre los dos (hacer lo que pueda entre lo que quiere y lo que debe), y construir identidades comprometidas que tampoco recubrirán nunca completamente a las otras dos. Si bien esto 
se aplica a cualquier sujeto, lo singular es cómo, para este joven, la puesta en escena de esta experiencia particular de ambigüedad se da en la encrucijada cultural Taiwán-Argentina dentro de una transmisión transgeneracional.

La búsqueda de mayor respeto y no ser visto como un extranjero forma parte de mi angustia, definiéndola por no encontrar una posición bien definida, de decir soy de tal lugar. El taiwanés tiene la exigencia de ser perfecto, estar en el pequeño detalle, busca el desarrollo tanto profesionalmente como persona, con sus reglas de convivencia, cosas así. Los argentinos no se sienten tan sobreexigidos. Cuando nos fuimos de viaje a Taiwán, nos invitaban a comer con muchas reglas en el medio. Uno se siente como nervioso, sin libertad. Para el argentino no hay tantas reglas de convivencia con el otro que recién conoce

Se destaca la capacidad de invención de los sujetos y aparece por primera vez la pregunta por el deseo personal.

La mayoría de los hijos orientales siguen medicina, derecho, contadores. Supongo que a eso se le atribuye la manera en que considero las carreras. Sin embargo, estoy cayendo, de a poco, en que ninguna de esas grandes carreras con el peso socialmente atribuido son para mí. No encuentro aún lo que me apasiona. En las materias del colegio me iba bien. Una amiga argentina dice que me falta pasión para lo que estudio y eso pesa mucho.

En el proceso de reflexionar sobre el malestar de este joven surgen varias hipótesis. Siguiendo a Bajoit (2009), podemos ilustrar desde las áreas de identidades, ya que si se separan las unas de las otras, se engendra una sensibilidad, un malestar identitario. Esto explica el hecho de que no logre conciliar pasión, deseo y estudio al afrontar una opción difícil, y asumir renuncias a partir de la palabra de la generación I, que actúa a la manera de reubicar su perspectiva hacia cuestiones de la propia cultura (el exigirse, el sentido del deber ...).

Después de hablar con mi mamá, me volví al eje que había perdido. Me devolvió la razón principal por la que había elegido la carrera de xxx...Para ella, si sigo la carrera de xxx, capto el mercado chino. Me había olvidado 
totalmente de ese detalle. Mi mamá hizo hincapié en la meta diciendo "tu carrera no te tiene que gustar, lo que te tiene que importar es que es tu futuro, los sentimientos que puedas tener con respecto a la carrera se pueden adquirir, no son natos, tiene que ser sí o sí xxx y no otra carrera, porque en otras carreras no vas a ser nadie, siendo xxx vas a poder levantar la cabeza”. Tenía razón en todo lo que dijo. Ya no pasa por si me gusta o no.

Otra hipótesis es que estas contradicciones que vive entre lo que dice ser, entre lo que es y quisiera ser, le generarían tensiones (una por parte de lo que le dice la amiga y otra de lo que le dice su madre) que afectan la invención de su identidad intercultural, poniendo en movimiento pendular tristeza y enojo.

\section{Caso 2: ¿Soy “Mei" o “María” (Generación II)?}

I - ¿Donde está María?

-¿Quién? Nosotros solo nos conocemos aquí por nuestros nombres chinos.

-Mi hermano y yo tenemos nombre chinos. Nuestros amigos argentinos nos llaman María y Hugo, pero nuestros nombres de verdad son otros. Nos pueden llamar de cualquier forma en realidad. Mi nombre no es de verdad.

I-Y María, ¿¿de dónde surgió?

-En el jardín me dijeron " ¿no tienes otro nombre que no sea este tan complicado?”. De chica jugaba con una chica que se llamaba María y me gustó el nombre. Fue mi mejor amiga de chica y, bueno, de ahí que me quedó María.

El nombre es un elemento que no solo permite identificar a las personas, sino que también permite vincularlas con una determinada formación étnica cultural. Este nombre expresa un hecho sociocultural y actúa como anuncio del "quién soy". Para Laurence Cornú (2004) el nombre propio es la metáfora de un lugar vinculante y disponible.

Mijail Malishev (2007) dirá que el reconocimiento de los demás a la propia identidad se expresa en la nominación, esto es, en la adquisición de un nombre que le garantiza a su portador la 
identidad en todos los campos posibles y en todos los periodos diversos de su vida, desde su nacimiento hasta la muerte. Reconocer a alguien es, en primer lugar, discernir su nombre. Dicho en otras palabras, el nombre propio es un soporte del reconocimiento social que otorga a su portador un conjunto de propiedades y atribuciones válidas para todos los ambientes posibles y que constituyen, a su vez, la base de las identidades socialmente construidas.

En tanto personas, poseemos un nombre y una singularidad. Esta, en primera instancia, tiene su sede en el cuerpo y sobre todo en el rostro. La imagen fotografiada de nuestro rostro se testimonia en el pasaporte, la licencia de conducir, o cualquier documento que necesite establecer nuestra identidad.

Resulta claro que decisiones como "me llamo María o Mei" pueden tener implicaciones en su historia por la fuerte carga sociocultural de una discriminación étnica que está detrás de situaciones de subestimación. Podríamos decir que, en lo que respecta a este fenómeno, los procesos identitarios contemporáneos son complejos pues, muchos de estos cambios de nombre tienen como base la búsqueda de nombres que sean menos susceptibles a la risa de parte de la sociedad anfitriona o funcionan a la manera de estrategias adaptativas. ${ }^{8}$ ¿Es que acaso este traslado del nombre busca la "invisibilidad" del ser taiwanés?

Parece que están siempre contentos, que nunca pasa nada, y en el fondo sufren una barbaridad. Yo fui tutor de ellos en su momento y tenía un grupo que eran tres o cuatro y ahí me di cuenta de muchas realidades, de muchos dolores, de muchas angustias que sufren y que nunca lo dicen, que siempre callan porque están acostumbrados a callar, es decir, siempre la orden del superior, del padre, del tutor o de quien fuera es sagrada y no se discute; y acá discutimos todo

Docente escuela argentina

Aunque por apariencia sea oriental, para nosotros, si el descendiente es nacido en Argentina, nunca será chino, nunca será taiwanés. ¿Qué clase de chino puede ser? Yo lo que le digo es "tienes que saber que aunque no

\footnotetext{
${ }^{8}$ Pensemos en los apellidos de inmigrantes polacos, árabes, italianos... que son españolizados en su pronunciación o directamente cambiados.
} 
sos chino, pero sos hijo de chino, entonces tenemos que transmitirte diferente pensamiento, diferente cultura, diferentes costumbres".

Directora escuela china

¿Qué tramitación tiene el malestar identitario de los alumnos inmigrantes dada su importancia dentro del proceso de construir identidades interculturales? ¿Cómo puede la escuela revertir estas experiencias traumáticas? ¿Qué rasgos de la forma escolar alientan estos padecimientos? Siendo la escuela el espacio de formación por excelencia, ¿trabaja para desarrollar experiencias de afirmación, negación o imposición de identidades interculturales?

\section{Caso 3: ¿Ser o parecer? K. (Generación III)}

-Es como que no puedo sacar lo oriental de mi vida y lo occidental tampoco. I -¿Qué de lo oriental te gusta y te niegas a dejarlo?

-Lo que pasa es que de lo oriental no conozco mucho, entonces no sabría decirte con certeza qué es lo que realmente me gusta.

-No me gusta lo oriental, no me gusta la música oriental, no me gusta el chino...

-Nunca me interesó ver películas en chino, nunca me relacioné con orientales.

-Mi hermano discrimina lo oriental, no le gusta para nada.

-Si tuviera hijos y siendo oriental me gustaría mandar a mis hijos a un colegio oriental y que lo terminen, que sepan chino, que tengan más cultura oriental, que no pierdan eso que yo sí lo he perdido. Yo quise dejar de ir al colegio, así que yo tuve la culpa también, en parte porque uno, si quiere, puede tener amigos orientales e ir a buscarlos.

Pierre Bourdieu (1990) con el concepto de habitus nos da algunas pistas para comprender esta nueva forma de malestar identitario que, bajo la forma de expresiones incoherentes, se manifiestan en K. En este sentido, dice "el habitus no está necesariamente adaptado ni es necesariamente coherente. Tiene sus grados de integración, que corresponden, en particular, a grados de cristalización del estatus ocupado". Se observa así que, a posiciones contradictorias, corresponden a menudo habitus desga- 
rrados, dados a la contradicción y la división contra sí mismos, generadora de sufrimiento.

En el colegio argentino yo jugaba con muchos compañeros pero mucho no entendía. Supongo que empecé a hablar bien el castellano a partir de quinto grado recién. Yo me comunicaba con la gente, me llevaba muy bien, pero es como que no entendía mucho

Este aspecto del habitus, según Bourdieu, nos indica que los sujetos pueden desarrollarlos aunque no se correspondan con las estructuras institucionales y provoquen en ellos una especie de desubicación en relación con su contexto. Es así, agrega, que los habitus cambian sin cesar en función de las experiencias nuevas. Las disposiciones están sometidas a una especie de revisión permanente, pero que nunca es radical, porque se lleva a cabo a partir de las premisas instituidas en el estado anterior.

Los cambios, entonces, se generan en el aspecto estructurante del habitus, pero requiere de pautas institucionales mínimas que lo posibiliten. Por otro lado, la acepción de "identidades" que adherimos no es algo construido, sino en construcción; por ende, podemos hablar de redefinición de identidades, modificación del habitus.

Yo me siento observada, ya cuando voy a la provincia me da un poco de miedo en el sentido de ¿qué pensarán? Lo mismo en el secundario, por ejemplo, cuando daba apoyo escolar al Colegio R, que estaba al lado de mi colegio, yo digo “¿Qué pasará con los alumnos? ¿Me harán burlas, bromas?”. Yo siempre tengo ese temor porque los niños son muy crueles. La verdad es que, por suerte, no me han hecho burlas, ni nada

Tengo como una anticipación de que puede pasarme algo. Porque hay algunos que capaz uno no dice algo correctamente, el profesor se enoja, entonces yo siempre me persigo, digo "me estará discriminando, no me quiere dejar pasar el examen porque soy oriental". Es como que todo el tiempo me persigo, pero bueno, siempre trato de no pensar que todo el mundo me quiere discriminar no, tampoco. 
Vemos cómo hay sensaciones de discriminación que, bien pueden ser padecidas, bien pueden ser pensadas.

En la actualidad se suele discutir la estigmatización social como si se tratara solo de problemas de personalidad. Parece suficiente que alguien crea que enfrenta una perspectiva amenazadora para hacerle temer. El enojo que K siente cuando recibe una ofensa que, ella cree, deviene por ser "china", está indicando que otorga más importancia a sus rasgos de lo que ella pensaba. También el enojarse con las personas que la tratan en forma grosera, podría ser también la actualización de maltratos sufridos por sus antecesores (Marta Nussbaum, 2006).

Mi papá no me dejaba tener malas notas, no me dejaba que me vaya mal porque si me iba mal, me castigaba. Por ejemplo, me hacía sentar a escribir dos o tres horas mi nombre chino, porque no lo sabía, pero para mí era una tortura, yo me tenía que sentar. Era muy chica. Acá yo creo que esas cosas no se hacen, es como más liberal.

Cuando mi hermano era mal alumno mi papá se enojaba. Y yo tenía que tratar de explicarle que no era tan así, que se calme, que no era para tanto. En la primaria, en el cuaderno rojo le ponían una notita informando al padre del bajo rendimiento. Lo contestaba yo y mi papá firmaba. Lo que pasa es que mi papá ahora me hace caso, bastante. Es como que yo le digo algo y mi papá hace más o menos lo que yo digo. Yo lo hice flexible a mi papá, de alguna u otra forma yo lo ablandé y ahora mi hermano, por ejemplo, no tiene problemas con mi papá para salir ni nada

Este pasaje de rigidez a flexibilidad puesto en la figura del padre como producto de su accionar pasa a formar parte de ella: no ya una diferencia que deviene en identidad y se rigoriza como tal, sino su apertura al flujo del devenir como flujo de la propia subjetividad.

Las identidades interculturales de estos jóvenes se caracterizan por estar en constante proceso de construcción y deconstrucción a la manera de inscripción en una nueva escena, una nueva novela familiar (Sigmund Freud, 1908). De ninguna manera los caracteriza la pasividad. 


\section{MANERAS DE TRAMITAR EL MALESTAR:}

Mercedes Minnicelli (2004) parafrasea la pregunta de Goethe "¿Qué te han hecho, a ti, pobre niño?" y comenta cómo "Los años de aprendizaje de Wilhelm Meister" fue transformada por Freud sentando bases para una posición diferente ante el sujeto expuesto a vicisitudes perjudiciales: “¿Qué vas a hacer, tú, con lo que te han hecho?".

Allí donde la transmisión se manifiesta como un desencuentro transgeneracional en el que los mayores tratan de imponer sus propios presupuestos socioculturales para garantizar la continuidad y sobrevivencia de las pautas de su cultura, se darían dos movimientos. Uno de resignación y aceptación de las jóvenes generaciones y otro como un convite a inventar la propia subjetividad.

A partir de incorporar el enfoque "transgeneracional" anudado con lo intercultural comenzamos a descubrir la existencia en la cadena de pasadores, un estar entre fronteras, presente en quienes no terminan de aceptar que han dejado algo y tampoco terminan de aceptar quedarse. Ello tendría impacto en los jóvenes de la tercera generación y su capacidad de invención en la búsqueda de sus identidades.

Es como algo que no se entiende bien. Si tenían mis papás un buen trabajo, un estudio, tengo todo, ¿por qué a ir a otro país que no sé ni el idioma y encima, a la otra punta del mundo? No los comprendo en realidad

M. (Generación II)

Vine hace nueve ańos sin saber el idioma. Pero cuando vine a Buenos Aires no entendía nada y le pregunté a mi familia: ¿¿Por qué vinimos a parar acá?

T. (Generación II)

En estos reclamos, y a la manera en que lo explica Michel De Certeau (1996) puede decirse que los sujetos se hacen un espacio, un atajo, y firman su existencia como actores y autores. Buscan esos intersticios a través de los cuales transitar en forma alternativa sus trayectorias. 
Hay una familia conocida de mi madre, que los dos hijos no tienen relación con chinos, mejor dicho, no les gustan demasiado tratar con chinos. Comen comidas argentinas y los amigos de los hijos son solo argentinos

L. (Generación III)

También están quienes rechazan su herencia sin importarles cuanto los separará de sus ascendientes. La rebelión aparece como capacidad de invención de los sujetos para tramitar su clivaje.

A mi hermano yo, a veces, le hablo en chino en la calle a propósito, y mi hermano dice "cállate, cállate". Dice "no me hagas pasar vergüenza".

Si en la escuela tenía que elegir algún país, yo nunca elegía un país oriental. Siempre elegía un país occidental.

M. (Generación II)

Este querer ser distinto lo aleja de sentir vergüenza, explicada por Hasoun (1996), cuando habla de contrabandear la memoria como ese intento de "desprenderse de la pesadez de las generaciones precedentes para reencontrar la verdad subjetiva de aquello que contaba con fuerza para quienes, antes que nosotros, amaron, desearon, sufrieron y gozaron por un ideal". Aclara después: "Aunque seamos rebeldes o escépticos frente a lo que nos ha sido legado y en lo que estamos inscriptos, que adhiramos o no a esos valores, no excluye que nuestra vida sea más o menos deudora de eso." Hay un querer diferenciarse o separarse de lo precedente sin poder reconocer el valor de estas elaboraciones que podrían dar sentido a su presente

Cuando yo salía de noche o me quedaba a dormir en la casa de amigos o de mi novio, mi papá ponía mala cara, no le gustaba. Me decía "te parece llegar a estas horas". No le gustaba mucho. Mi papá es muy estricto aunque igual yo sigo saliendo.

M. (Generación II)

La afirmación foucaultiana (1980) "donde hay poder hay resistencia” encuentra cabida en este comentario teñido de desobediencia y transgresión. Foucault destaca el carácter coextensivo y 
contemporáneo de las resistencias. Su mirada se desplaza desde la constatación de la reproducción de lo ya dado hacia la potencialidad de transformación de lo existente.

Podríamos sostener que las lógicas de operación, al ser rutinizadas, si bien intentan constreñir a estos actores, fijan unos márgenes. Aún así, hay una franja de indeterminación relativa, que deja espacio para la rebeldía, además propia de esta etapa etaria.

Los chicos nacidos en Argentina ya crecen con el idioma español. Hay familias taiwanesas que también ya hablan en español y el taiwanés y por eso a los hijos les cuesta o no les gusta ir al colegio chino.

K. (Generación III)

De chiquita siempre me gustaba más comer fideos con tuco que comer el arroz. El fideo lo terminaba y el arroz no. No me gustaba.

L. (Generación III)

Vienes al colegio chino y hablas con tus compañeros en castellano.

F. (Generación II)

Hasoun (1996) aporta que la recepción de las palabras y los actos que vehiculizan la herencia implican movimiento, ya que es fundamental el reconocimiento que se hace de aquel a quien se autoriza como transmisor. El descendiente no es una víctima pasiva a merced del progenitor.

Mamá hace tiempo que cedió su autoridad. Lo único que me exigía, era asistir a la Iglesia todos los domingos.

L. (Generación III)

Estamos ante una concesión que hace la madre que opera mediante una negociación a la manera de una trasgresión oficializada: "Yo cedo, pero exijo que sigas con los dispositivos rituales".

Mis padres tienen la noción de ser muy ahorrativos. No sucede eso en mi generación. Para mi generación yo gano el dinero, y si bien tengo la opción de guardarlo, también quiero aprovecharlo. Pero ellos (mis pa- 
dres) es como que todo lo quieren guardar, por las condiciones que han atravesado.

T. (Generación II)

De acuerdo a la teoría de Pierre Bourdieu (1990), las prácticas culturales en movimiento y la cultura objetivada se articulan mediante el habitus (cultura incorporada). El habitus destraba el problema del sujeto individual al constituirse en el lugar de incorporación de lo social en el sujeto, lo que permite colocar al centro de la reflexión una subjetividad modelada, configurada y enmarcada por un conjunto de estructuras sociales objetivas de carácter histórico que él incorpora de acuerdo con el lugar y el tiempo que ocupa en dicha estructura. Bourdieu propone el habitus a la manera de un conjunto de disposiciones lógicas y afectivas, ergo su teoría abre la posibilidad de entender la negociación entre sujetos históricos y situados y las estructuras que los han formado como tales; negociación que se verifica en la práctica, es decir, en la puesta en escena de los valores y saberes incorporados (el habitus) que se enfrentan a su pertinencia y validación en la situación social en la que éstos son desplegados.

El respeto es tan fuerte y hasta agresivo si se quiere, porque es un sometimiento hasta físico. Yo tengo el caso de un chico de este colegio que los padres le pegaban muy mal, le pegaban hasta con elementos. No usaban solamente las manos y, sin embargo, le digo "¿renegarías de tus padres?", "no nunca". Ni se le ocurre. Como que hay un gen, un "chip" que tienen: "no te rebeles contra tus padres porque es lo más grave que puede suceder en la vida". Que yo no esté de acuerdo con lo que ellos hagan, es una cosa, pero el respeto que tengo hacía ellos es casi milenario como la misma cultura. No lo pueden renegar, por más que quisieran. Yo noto que el chico me puede plantear que no le gusta lo que los padres hacen, que le tiene miedo al papá, pero en el fondo, es su papá y no va a renegar de él.

Docente escuela argentina

Acudir a Pierre Bourdieu (1990) contribuye a discernir sobre la tensión perceptible en el trabajo de campo entre el sujeto-sujetado (propio del estructuralismo); el sujeto reflexivo capaz de resistencia (propio de la sociología comprensiva) como en este caso 
bajo el dispositivo del idioma, o los valores; y el sujeto hablante que no es tal sin enunciación dirigida, sin palabra, ni sin lengua en tanto estructura (propio del psicoanálisis).

Si los esquemas usados y tomados por valiosos necesitan ser readaptados, se produciría un desajuste o una ruptura entre la práctica y dichos esquemas, lo que genera movimientos en el habitus. En los esquemas de percepción, valoración y acción sobre el mundo social, se pone en evidencia una capacidad afirmativa, creativa y fundante de las resistencias, que adquieren para Michel De Certeau (1996), una inteligibilidad propia.

He visto ceremonias, por ejemplo que los paisanos en los funerales tiran petardos, y yo digo ¿qué pasa acá? Alguien se muere y ¿empiezan a tirar cohetes, petardos? ¿Cómo puede ser esto? Entonces mi papá me contesta "pero acá la gente aplaude cuando uno se muere, cuando pasa el ataúd. Yo no entiendo cómo van a aplaudir”.

M. (Generación II)

El debilitamiento del sentido otorgado a ciertas prácticas instaladas en este grupo, a causa de esos desajustes, generaría una falla, una avería o incumplimiento en los presupuestos de la vida cotidiana.

En mi casa mi papá, ya en el preescolar me enseñaba a sumar y restar, todo mental. En primer grado nos decían "traigan fósforos", y mi papá no quería que lleve fósforos, entonces, tenía un signo menos en materiales para llevar al colegio y siempre tenía todo negativo porque mi papá no quería que yo use la técnica que enseñaba el colegio, porque no la entendía.

T. (Generación II)

Es posible también plantear la situación inversa, los postulados que los mayores no comprenden tratan de debilitarlos a través de la imposición de sus propios presupuestos socioculturales para garantizar la continuidad y sobrevivencia de las pautas de su cultura. Adultos y jóvenes portadores de culturas diferentes y, por tanto enfrentados en sus concepciones vitales.

Cuando fui a Taiwán por dos meses, mi abuela dijo que era mucho tiempo; entonces, nos mandó a la escuela. Al colegio ese fui un poquito con la cultu- 
ra de acá también, o sea era un poquito más viva. Ahí eran más honestos. Si tenías un error, lo decías; entonces, ibas y te castigaban. Yo tenía un montón de errores y lo que hice fue, bueno cerré el cuaderno y lo escondí abajo del banco. Entonces me preguntaban “¿cuántos errores tienes?”. "Ninguno”, dije, y como no te revisaban, entonces ahí me salvé del castigo".

K. (Generación III)

Nuestros mayores dan mucha importancia al cálculo mental y se contradicen con los métodos de enseñanza de aquí que usan materiales concretos. Mi compañera, llevaba los materiales pero igualmente, lo hacía mental.

Y. (Generación III)

De Certeau (1996) nos propone pensar en la indeterminación como característica constitutiva de una relación de poder. Los argumentos de este autor explican el proceder de las dos respuestas en tanto apuestan a la creatividad que, elusiva, dispersa, fugitiva, hasta silenciosa, fragmentaria, y artesanal construye maneras de hacer, maneras de circular, habitar, leer, estudiar, etc. Se trata según él, de grietas que dan lugar a lo que denomina "tácticas del débil”, entendidas como esas acciones pequeñas, individuales que desafían de algún modo el poder. Este autor sostiene que esas pequeñas acciones van dejando huellas, marcas en el sistema. Son como gotas de agua que van horadando la piedra.

Con mi hermana hablamos en castellano cuando no queremos que nuestros padres se enteren de algo que a ellos no les gustaría.

L. (Generación II)

Lo que pasa que jóvenes ya tienen más individualidad, pueden autoelegir. Entonces, cuando los padres les dicen de aprender un idioma los chicos dicen "mejor no aprendo ¿para qué?, si estoy en Argentina”.

Docente escuela china

Para De Certeau (1996), todo poder tiene como contrapartida un micro contrapoder (la cultura receptora impactando en la construcción de autoridad de la Generación I) Analizar la cultura, sería analizar esos atajos que usan las Generaciónes II y III, a modo de tramitar aquello que reciben de sus mayores.

Apreciaciones de un docente argentino entrevistado dan cuentan de resistencias pasivas que los alumnos aplicaban para manifes- 
tar su disconformidad a ser inmigrante en un país que no eligieron. Por ejemplo al extremo de actuar con total desidia en la clase para reprobar. Esta focalización que él nos trae ayuda a apreciar acciones de resistencia, gestos que De Certeau llama "micro revoluciones". Bourdieu (1990), al contrario de De Certeau, no deja margen a las brechas, a los márgenes. Para él no toda rebeldía es liberadora.

La pregunta que queda es ¿Hasta qué punto los sujetos en el cruce de la interculturalidad y las transgeneracionalidad vivirán sin culpa las tácticas de rebeldía? Teniendo en cuenta la sumisión propia de su cultura ¿Podrán defender ante sus mayores su independencia ya que no son programables como ellos esperan?

\section{CONCLUSIÓN}

Este artículo trató de demostrar el impacto de los procesos migratorios e inferir cómo se recuperan las formas en que los estudiantes inmigrantes construyen sus identidades, en el contexto escolar y social.

Es claro que ello plantea muchas incógnitas. Nuestra propuesta es que en el anudamiento entre lo transgeneracional y lo intercultural, queda ubicado el sujeto-alumno, que buscará reinventarse en el vínculo para sobrellevar su padecimiento.

Ante la transmisión transgeneracional estos estudiantes lidian de diversos modos con el arquetipo de una mera repetición del pasado y/o una transmisión que habilita interrupción, trasgresión, la traición en el pasaje de lo uno a lo otro.

Los fragmentos de entrevistas usados muestran algunos de los alcances de su rebeldía y los efectos significativos de ella en tanto herramienta para sobreponerse a la intensidad del malestar identitario.

Si bien trabajamos con una comunidad hibridada en un "espacio público expandido" (Reguillo Cruz, 2000) con fronteras porosas, permeables, alternativas... todo ello supone elaboraciones de nuevos sentidos, que resultan complejas, crean inseguridad y se tramitan por depósitos de viejos sentidos que direccionan sus acciones hacia un sin sentido expresado en ambigüedades y malestar.

Sin embargo creemos que existe en todo sujeto la capacidad de crear nuevas formas, de sustraerse de imaginarios cristalizados, preinstituidos ya que el contacto entre culturas impulsa la reinvención de tradiciones e invención de identidades "para no- 
sotros" y "para los otros". Y la escuela es el lugar donde puede y debe ofrecer lugares para que ello suceda.

Esto coloca a los formadores ante el desafío de entender que la heterogeneidad se da por la concurrencia en una misma clase de estudiantes con distintas procedencias socioeconómicas y culturales: familiares, lingüísticas, religiosas, políticas, culinarias, estéticas, corporales, científicas... encarnadas en los alumnos y que los convoca a revisar los nuevos sentidos del oficio de educar y el de capacitarse para sostener esa responsabilidad en el contexto de un mundo globalizado.

\section{REFERENCIAS BIBLIOGRÁFICAS}

Atkinson, P. y Silverman, D. Kundera's. Immortality. The interview society and the invention of the self. Qualitative Inquiry, citado en Bauman, Z. La modernidad liquida, Buenos Aires, Fondo de Cultura Económica, 2000.

Arendt H. "La crisis de la educación", en Arendt H. Entre el pasado y el futuro. Ocho ejercicios sobre la reflexión politica, Barcelona, Península, 1954.

Autés, M. "Tres formas de desligadura”, en Karsz, S. (coord), La exclusión: bordeando sus fronteras. Definiciones y matices, Barcelona, Gedisa, 2004.

Bajoit, G. "La tiranía del 'Gran ISA (Individuo-Sujeto-Actor)", en Revista virtual Cultura y representaciones sociales. Un espacio para el dialogo interdisciplinario", año 3, núm. 6, marzo, México, 2009. Disponible en http://www.culturayrs.org.mx/revista/num6/Bajoit.HTML. Fecha de consulta, junio de 2009.

Berenstein, I. y otros. Clínica familiar psicoanalitica, Buenos Aires, Paidós, 2000.

Bourdieu, P. Sociología y Cultura, México, Grijalbo, 1990.

Cesca P. Los alumnos inmigrantes. Malestar identitario en las aulas, Buenos Aires, Editorial Mandioca, Coleccion Caminos de Tiza, 2016.

Cornu, L. "Transmisión e institución del sujeto. Transmisión simbólica, sucesión, finitud", en Frigerio, G. (comp.). La transmisión en las sociedades, las instituciones y los sujetos, Buenos Aires, Noveduc/SEM, 2004. 
D'Certeau, M. La invención de lo cotidiano, 1. Artes de hacer, México, Universidad Iberoamericana/ITESO/Centro de Estudios Mexicanos y Centroamericanos, 1996.

Deleuze, G. Lógica de sentido, Buenos Aires, Paidós, 2003. Derrida, J. De la gramatología, México, Siglo XXI, 1986.

Fitoussi, J. y Rosanvallon, P. La nueva era de las desigualdades. Buenos Aires, Manantial, 1997.

Foucault, M. Microfísica del poder, Madrid, La Piqueta, 1980.

Freud, S. "La novela familiar", en Obras completas Tomo IX, Buenos Aires, Amorrortu, 1978.

Ginzburg, C. Ritos, emblemas e indicios, Barcelona, Gedisa 1986. Guber, R. El salvaje metropolitano, Buenos Aires, Legasa, 1991.

Hassoun, J. Los contrabandistas de la memoria, Buenos Aires, Ediciones La Flor, 1996.

Hunter, I. Migración, Cultura e Identidades, Buenos Aires, Amorrortu, 1994.

Malishev, M. Vivencias afectivas: Expresión de la existencia humana, México, Plaza Valdez, 2007.

Minnicelli M. Infancias públicas no hay derechos, Buenos Aires, Ediciones Novedades Educativas, 2004.

Nussbaum, M. El ocultamiento de lo humano. Repugnancia, vergüenza y ley, Buenos Aires, Katz editores, 2006.

Pestre, E. "Lo traumático en las transmisiones: El caso de los exiliados", en Jornadas organizadas por el Programa de Investigación, formación y clínica socioeducativa del área de educación de FLACSO (septiembre, 2009).

Reguillo Cruz, R. "El otro antropológico. Poder y representación en una contemporaneidad sobresaltada", en Análisis. Cuadernos de Comunicación y Cultura, núm. 29, Antropología de la Comunicación, Barcelona, Universidad Autónomas de Barcelona, 2000.

Roudinesco E. y Plon M. Diccionario de psicoanálisis, Buenos Aires, Editorial Planeta, 1997.

Saltalamacchia, H. El proyecto de investigación: su estructura y redacción, Puerto Rico, Cuadernos de CAPEDCOM, 1997. 